\title{
Development of substorm cross-tail current disruption as seen from the ground
}

Article

Published Version

Gazey, N. G. J., Lockwood, M., Smith, P. N., Coles, S., Bunting, R. J., Lester, M., Aylward, A. D., Yeoman, T. K. and Lühr, H. (1995) Development of substorm cross-tail current disruption as seen from the ground. Journal of Geophysical Research, 100 (A6). p. 9633. ISSN 0148-0227 doi: https://doi.org/10.1029/94JA02322 Available at https://centaur.reading.ac.uk/38803/

It is advisable to refer to the publisher's version if you intend to cite from the work. See Guidance on citing.

Published version at: http://dx.doi.org/10.1029/94JA02322

To link to this article DOI: http://dx.doi.org/10.1029/94JA02322

Publisher: American Geophysical Union

All outputs in CentAUR are protected by Intellectual Property Rights law, including copyright law. Copyright and IPR is retained by the creators or other copyright holders. Terms and conditions for use of this material are defined in the End User Agreement.

\section{www.reading.ac.uk/centaur}

\section{CentAUR}


Central Archive at the University of Reading

Reading's research outputs online 


\title{
Development of substorm cross-tail current disruption as seen from the ground
}

\author{
N. G. J. Gazey, ${ }^{1,2}$ M. Lockwood, ${ }^{1,3}$ P. N. Smith, ${ }^{2}$ S. Coles,${ }^{2}$ R. J. Bunting, ${ }^{4}$ \\ M. Lester, ${ }^{5}$ A. D. Aylward, ${ }^{1,6}$ 'I'. K. Yeoman, ${ }^{5}$ and H. Lühr ${ }^{7}$
}

Abstract. We discuss substorm observations made near 2100 magnetic local time (MLT) on March 7, 1991, in a collaborative study involving data from the European Incoherent Scatter radar, all-sky camera data, and magnetometer data from the Troms $\varnothing$ Auroral Observatory, the U.K. Sub-Auroral Magnetometer Network (SAMNET) and the IMAGE magnetometer chain. We conclude that for the substorm studied a plasmoid was not pinched off until at least 10 min after onset at the local time of the observations (2100 MLT) and that the main substorm electrojet expanded westward over this local time $14 \mathrm{~min}$ after onset. In the late growth phase/early expansion phase, we observed southward drifting arcs probably moving faster than the background plasma. Similar southward moving arcs in the recovery phase moved at a speed which does not appear to be significantly different from the measured plasma flow speed. We discuss these data in terms of the "Kiruna conjecture" and classical "near-Earth neutral line" paradigms, since the data show features of both models of substorm development. We suggest that longitudinal variation in behavior may reconcile the differences between the two models in the case of this substorm.

\section{Introduction}

Interest has recently focused on the location of substorm onset with relation to the open/closed field line boundary. The classical near-Earth neutral line (NENL) model of substorms has been the widely accepted explanation of substorms for several years. According to this model, onset occurs on field lines that map to the near-Earth neutral line, where reconnection takes place rapidly in the expansion phase of a substorm, leading to the closure of open flux shortly (1-5 min) after onset. The neutral line disrupts the cross-tail current in the plasma sheet, giving the many signatures of the "current wedge" as the cross-tail current is diverted through the ionosphere. Data from the Active Magnetospheric Particle Tracer Explorer Ion Release Module (AMP'IE-IRM) have shown that the near-Earth neutral

\footnotetext{
${ }^{1}$ Rutherford Appleton Laboratory, Chilton, England.

${ }^{2}$ Space Science Centre, Sussex University, Brighton, England.

${ }^{3}$ Blackett Laboratory, Imperial College, London.

${ }^{4}$ Department of Physics, York University, York, England.

${ }^{5}$ Department of Physics and Astronomy, Leicester University, Leicester, England.

${ }^{6}$ Atmospheric Physics Laboratory, University College, London.

${ }^{7}$ Technische Universität, Braunschweig, Germany.
}

Copyright 1995 by the American Geophysical Union.

Paper number 94JA02322.

0148-0227/95/94JA-02322\$05.00 line rarely forms inside $19 R_{E}$ [Baumjohann et al., 1991, 1992]. However, a number of studies have provided evidence that substorm onset occurs much closer to the Earth [Murphree et al., 1993; Elphinstone et al., 1991; Elphinstone and Hearn, 1993; Lopez et al., 1991, 1992, 1993; Ohtani et al., 1992a,b; Baker et al., 1993; Samson et al., 1992a,b]. An alternative substorm model, which gained wide acceptance at the 1992 Kiruna conference on substorms, is that onset happens at approximately $8 R_{E}$ on closed field lines, and is not due to local reconnection, but rather to some other kind of disruption of the near-Earth cross-tail current. In the ionosphere, this means that evidence for onset should be seen equatorward of the open/closed field line boundary. We present measurements made with the European Incoherent Scatter radar (EISCAT) during active substorm conditions and investigate the possibility that EISCAT was on closed field lines even though the substorm onset region and associated electrojet were to the south of the radar, while the open/closed field line boundary would seem to have been to the north. The length of time for which this situation persisted (about $10 \mathrm{~min}$ ) can not be explained by the classical near-Earth neutral line model, in which Troms $\varnothing$ should have been on open ficld lines shortly after an onset occurring to the south.

In the classical near-Earth neutral line model [Hones, 1976], the buildup of magnetic flux in the tail during periods when the Interplanetary Magnetic Field (IMF) is southward (the growth phase) causes the plasma sheet to thin and a reconnection neutral line to form across the tail (Figure 1). The NENL forms earthward of the 
(a)

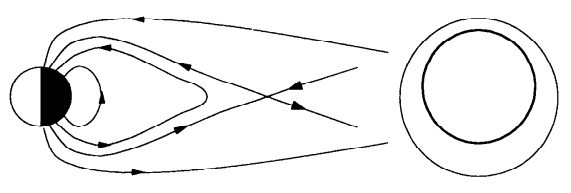

(b)

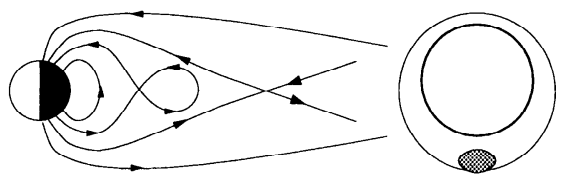

(c)

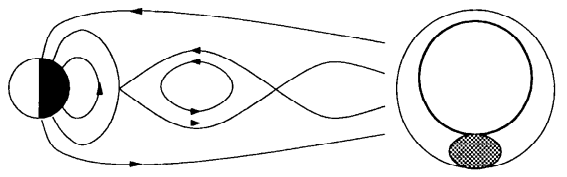

)

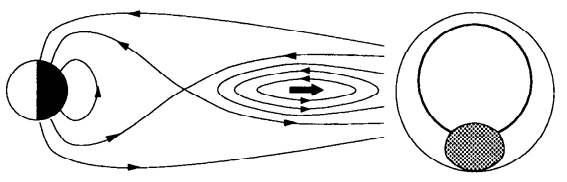

(d)

Figure 1. Schematic of four stages of tail evolution during a substorm as predicted by the classical nearEarth neutral line (NENL) model. To the left are noonmidnight sections of the magnetosphere, with the Sun to the left, and to the right are the corresponding views of the northern polar ionosphere, from above, showing the auroral oval with the open/closed field line boundary at its poleward edge (dark line); 0000 magnetic local time (MLT) is at the bottom of the oval, and 1200 MLT is at the top. The shaded rcgion rcprescnts the area of the auroral substorm. (a) The situation late in the growth phase, with an active distant reconnection neutral line, (b) time of onset, caused by the formation of the NENL, (c) the instant of time when the plasmoid is pinched off, such that the NENL begins to close open flux, and (d) ejection of the plasmoid down the tail as open flux in the lobe is destroyed. In this model, the time between onset and pinch-off (depicted by Figues $1 \mathrm{~b}$ and 1c) is short, typically 1-5 min.

old neutral line, which may be as much as $100 R_{E}$ down the tail. At the first instant of formation, the NENL is on closed field lines, but within a minute or so, it has reconnected open flux such that a plasmoid is pinched off between the NENL and the old neutral line [Moldwin and Hughes, 1992, 1993]. The plasmoid travels downtail due to magnetic tension, which allows the NENL to relax downtail also. As the NENL relaxes tailward, so the open/closed field line boundary moves poleward in the ionosphere. This picture has been used to explain the poleward expansion of the auroral oval during the substorm expansion phase. In this model, therefore, the auroral oval brightens close to the open/closed field line boundary and expands poleward into the polar region, which was previously on open field lines. The fact that a bright auroral bulgc forms near midnight, only then cxpanding out in latitude and longitude, would indicate that the reconnection region is initially limitcd in longitudinal extent and gradually extends outward towards the magnetosheath flanks as time goes on. The formation of the near-Earth neutral line causes the cross-tail current to be diverted through the ionosphere, giving rise to the enhanced substorm electrojets and magnetic field dipolarization, as seen at geosynchronous orbit.

Two established aspects of substorm physics are well explained by the classical NENL model, namely, the decay of the lobe field and the formation of plasmoids (the term "classical" in this context is used to mean that the poleward expansion of the optical aurora is caused by closure of open flux, commencing almost at onset). A key point of this original version of the NENL model is that the lobe field begins to decay very shortly after onset, causing a plasmoid to become detached or "pinched off" from the Earth. Plasmoids have been observed via their magnetic signature by tail satellites such as ISEE 3 and are not satisfactorily explained without reconnection at a second neutral line, earthward of the distant neutral line. Slavin et al. [1992], who examined 36 consecutive hours of ISEE 3 tail observations, covering 14 substorms, found that each substorm yielded a plasmoid. Moldwin and Hughes [1992, 1993] showed that plasmoids are stable structures and can always be associated with a substorm. Plasmoids are also reproduced in MHD simulations of the magnetosphere [e.g., Birn and Hesse, 1991a,b]. Walker et al. [1992] found in simulations that a neutral line forms at $19 R_{E}$ approximately 1 hour after the IMF turns southward, a location which agrees well with the results of statistical surveys of AMPTE-IRM data and ion streams [Baumjohann ct al. (1991, 1992)]. The classical NENL model, as it stands, cannot explain onset much closer than about $19 R_{E}$.

The suggestion that onset occurs close to the Earth $\left(X \sim-8 R_{E}\right)$ is not new (see reviews by Galperin and Fcldstcin [1991] and Feldstein and Galperin [1993]). It has been argued on the basis of the Tsyganenko magnetic field models (valid when close cnough to the Earth), that the preexisting auroral oval, on which onset always occurs, should be equatorward of the open/closed field line boundary [Elphinstone et al., 1991; Murphree et al., 1993]. This concept fits in well with the doubleoval picture which emerged from VIKING UV auroral imager data from the substorm recovery phase [Elphinstone and Hearn, 1993; Murphree and Cogger, 1992].

The location of the most poleward arc at onset is equatorward of a band wherc weak UV emission still occurs, indicating that onset may well be equatorward of the open/closed field line boundary. The arc which advances farthest poleward during the substorm expansion phase lights up what would seem to be the open/closed field line boundary (since poleward of that, there are no emissions at any stage), and leads to the "double-oval" configuration.

There is now much evidence to support the idea that onset takes place near $8 R_{E}$. For example, Baker et al. [1993] used the Tsyganenko model, modified by Pulkki- 
nen [1991] (see also Pulkkinen et al. [1991a,b]) to allow for stretching of the tail, in order to map DE 1 and VIKING auroral images of substorm expansion back to the magnetotail. They found that the substorm onset region was located just tailward of geostationary orbit $\left(X \sim-7 R_{E}\right)$. A modification of the NENL model becomes necessary because although electrojet strengthening and dipolarization at onset require cross-tail current disruption, the current disruption in question cannot originate at the neutral line that forms somewhere beyond $19 R_{E}$, if the observations of onset near $8 R_{E}$ are to be believed. Cross-tail current disruption may not be due to a reconnection neutral line, but rather to an instability which drives the substorm electrojets and advances tailward as the auroral bulge expands. Current disruption in this picture is not a consequence of the the neutral line forming, but rather as a precursor to it (and possibly the causc of it).

The new view of the location of onset, well earthward of the open/closed field line boundary, has interesting implications for the timing of the phases of substorm development in the magnetotail and ionosphere, as is demonstrated by Figure 2. Slavin et al. [1992] studied the delay time between substorm onset and observation of the associated plasmoid, and found that the delay time lay in the range 5-30 minutes. They used Auroral Kilometric Radiation (AKR) activity, Pi2 activity, $A L$, and electron injection at geosynchronous orbit as indicators of onset time. While they attributed the large range of delay times to uncertainties, it is possible that the delay time between onset and plasmoid pinch-off (which in the classical NENL model is only of the order of a minute or so) may not be as short as was originally thought. Another feature of plasmoids which calls for a modification of the classical NENL model is that earthward of $100 R_{E}$, most plasmoids are bounded by earthward, or both earthward and tailward streaming ions [Owen and Slavin, 1992]. Farther out, only tailward ion streams are seen. This indicates that earthward of $100 R_{E^{\prime}}$, plasmoids may move downtail before being pinched off. Scholer and Hautz [1991] made a case for this, saying that plasma pressure is sufficient to move the proto-plasmoid tailward while closed field lines are still draped around it.

The revised picture, depicted in Figure 2, is a synthesis of the best features of the classical NENL and current disruption models and is termed the Kiruna conjecture [Kennel, 1992] after the location of the ICS-1 meeting on substorms where it received much attention. In this model, onset occurs at about $8 R_{E}$, as the near-Earth tail's response to the accumulation of open flux and plasma in the tail during the growth phase. In the ionosphere, this means that the brightening of the auroral oval will be equatorward of the open/closed field line boundary. The current disruption region moves tailward, causing the auroral bulge to move poleward, as observed, and may well evolve into a near-Earth neutral line at $X \sim 19 R_{E}$. Eventually, the poleward edge (a)

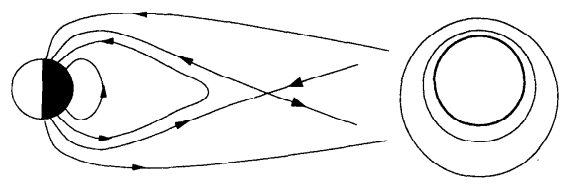

(b)

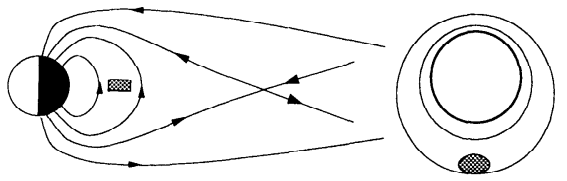

(c)

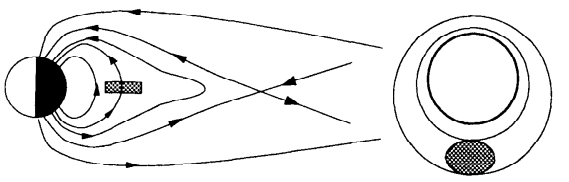

(d)

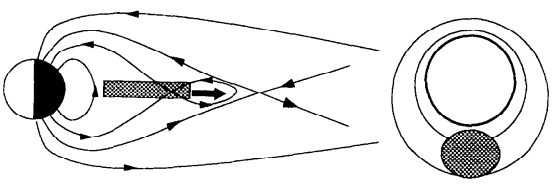

(e)

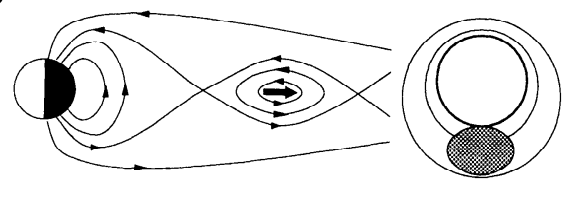

Figure 2. Schematic of five stages of tail field development in the "Kiruna conjecture" model of substorms. The format is as in Figure 1, other than for the square shaded region in the near-Earth tail, which is the location of the cross-tail current disruption that generates onset, and the thick ring, which rcprcsents the open/closed field line boundary, now poleward of the poleward edge of the auroral oval. (a) End of the growth phase, (b) onset, (c) expansion of the current disruption downtail, (d) formation of the NENL, and (e) the pinching off of the plasmoid. In this picture, there is considerable delay (of the order of 15-30 min) between onset and open flux starting to be destroyed at the NENL.

of the substorm cxpansion reaches the opcn/closcd ficld line boundary. This can be considered to mark the beginning of the recovery phase and can be interpreted as the point when the NENL begins to reconnect open flux, i.e., the point that the plasmoid is pinched off. The plasmoid moves downtail due to plasma pressure, whether or not it is still embedded in closed field lines which might hinder its progress. The poleward edge of the auroral oval, lit up by the arrival of arcs from lower latitudes, gives rise to the double oval configuration noted in VIKING imager data during the recovery phase.

Despite its many successes, not all problems are solved by the new model. One key piece of evidence that is not well explained by this model, but is by the NENL model, is that the lobe field is seen to decay at onset [McPherron et al., 1993]. If this is not due to the destruction of open flux, a new explanation must be found before the new model is fully consistent with observa- 
tions. The debate about the "classical" NENL model and hybrid current disruption/NENL models has thus yet to be resolved.

\section{Data Sources}

On March 7, 1991, the EISCAT UHF radar was used to make measurements of electron density, electron temperature, ion temperature, and plasma velocity in the ionosphere. The EISCAT UHF system has three antennae, one situated at Troms $\varnothing$ in Norway, one at Kiruna in Sweden, and one in Sodankylä in Finland. The Troms $\varnothing$ dish acted as transmitter, and all three acted as receivers. The EISCAT data presented here come from a run of a variant of Common Programme One (CP1). The Troms $\varnothing$ antenna was pointed along the field line, and the remote EISCAT antennae were pointed so as to receive a signal scattered from the Troms $\varnothing$ beam at a height of $350 \mathrm{~km}$. The experiment used two pulse schemes, namely a long pulse to make measurements of the $F$ region and a multipulse for $E$ region measurcments. The range resolution of the long pulsc data was $22.5 \mathrm{~km}$, while multipulse measurcments had a range resolution of approximately $4.5 \mathrm{~km}$. On the night described here, the ionosphere was dense, and consequently the returned signal was strong enough for long pulse $F$ region data to be analyzed at 10 second post-integration at altitudes up to $575 \mathrm{~km}$. Multipulse data were analyzed at 1-minute resolution. Three-dimensional velocity vectors with 10 -s resolution were made by combining the Doppler velocity estimates obtained by each radar for the common scattering volume. Knowing the geometry of the three sites, it was possible to transform the three velocity estimates into a Cartesian coordinate system (field parallel and field perpendicular, north and east).

An integral part of the experiment was the operation of optical cameras at the Troms $\varnothing$ site, both to record the passage of arcs over the sky at Troms $\varnothing$ and to make measurements of optical intensity in the EISCAT beam itself. The all-sky images presented in this paper were produced by the Sussex University all-sky camera, which is sensitive to emissions between 400 and $1150 \mathrm{~nm}$ [Coles, 1992]. The luminosity measurements are absolute. Light was typically collected for $10 \mathrm{~s}$ per image. The length of each exposurc was varied so as to allow the camcra gain to be kept at its maximum sctting. The camera was situated a few hundred meters from the radar at Troms $\varnothing$. Computer analysis of video camera images also allows the auroral light intensity in the EISCAT beam to be extracted ( 6 pixels on a 256 by 256 pixel image corresponds to about $1^{\circ}$ beam width, compared with the $0.5^{\circ}$ beam width of the EISCAT radar beam).

We also employ ground magnetic data from three sources: the first is the SAMNET magnetometer chain, deployed and operated by the University of York [Yeo-

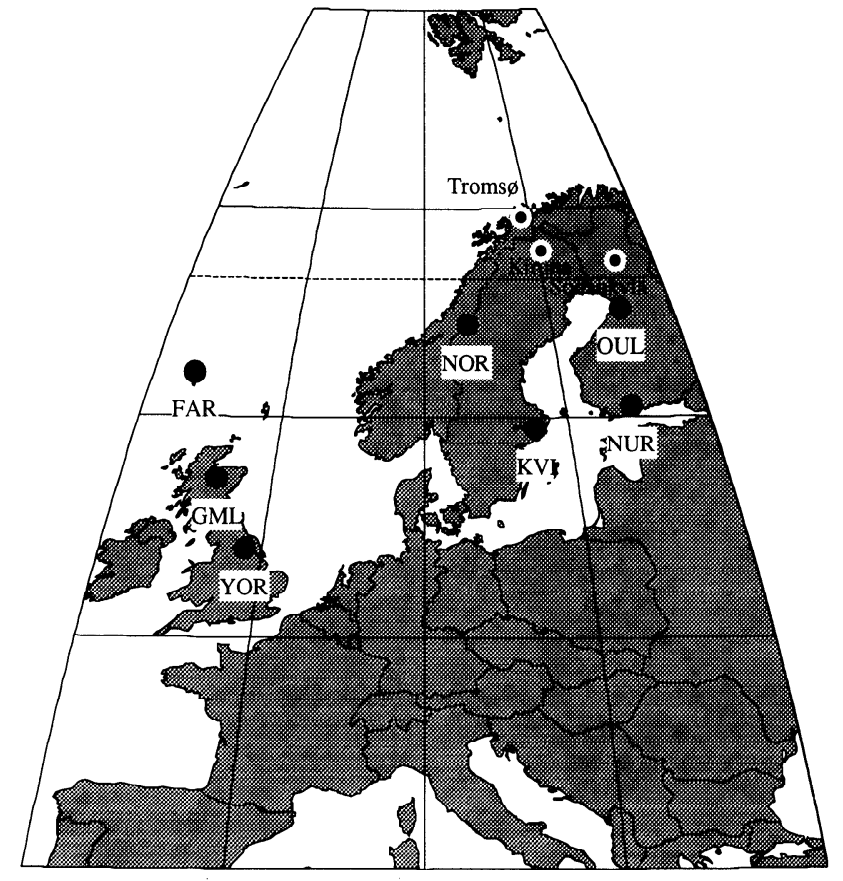

Figure 3a. 'I'he U.K. Sub-Auroral Network magnetometer sites.

man et al., 1990]. The SAMNET sites are shown in Figure $3 \mathrm{a}$. The second is the IMAGE magnetometer chain, deployed and operated by the Finnish Meteorological Institute, the Sodankylä Geophysical Observatory, and the Technische Universität Braunschweig [Lühr et al., 1984]. Figure 3 b shows a map of the IMAGE sites. The third is the Troms $\varnothing$ Auroral Observatory. IMF data were obtained from the IMP 8 satellite, which was located at GSE coordinates $(29.7,12.3,-15.1) R_{E}$.

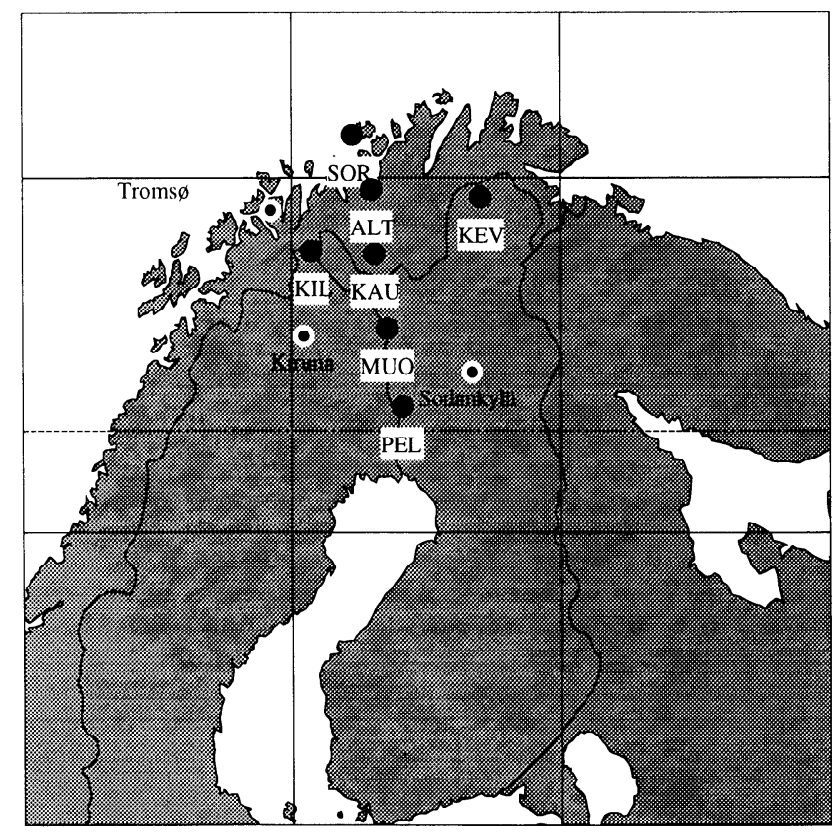

Figure 3b. The IMAGE magnetometer sites. 
It should be noted that the substorm studied here took place at around 1900 universal time (UT), which corresponds to about 2100 MLT. Hence the observations come from the middle of the premidnight sector and are to the west of the substorm onset region. This study has implications for the dusk flank of the magnetosphere but does not directly yield information about the region in the central tail where cross-tail current disruption first appears.

\section{Observations}

Between 1800 UT and 2400 UT on the 7.3.91, there were three clear substorm bays in the magnetometer record. We describe the first substorm, which began at about 1840 UT. Magnetic local time at Troms $\varnothing$ is approximately 2 hours ahead of universal time and therefore this first substorm started at approximately 2030 MLT. Figures $4 \mathrm{a}$ and $4 \mathrm{~b}$ show the magnetic field $X$ and $Z$ components, measured by the IMAGE magnetometers (see Figure 3b). Magnetometer data from the Troms $\varnothing$ Auroral Observatory for the same period are shown in the upper panels of Figure 7. The substorm expansion phase began at around 1837 UT with

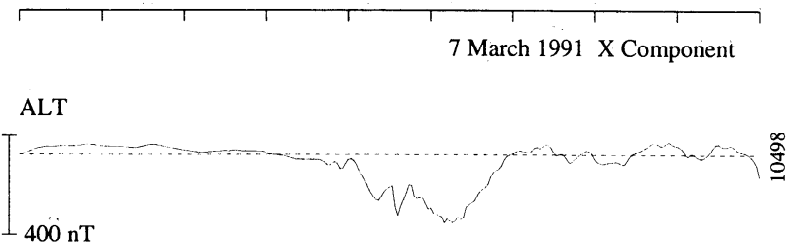

KIL

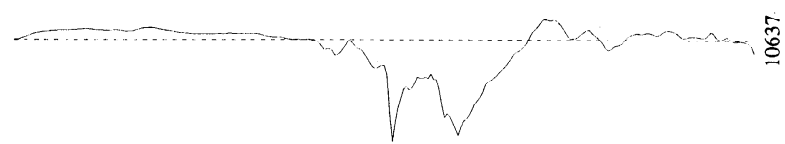

KEV

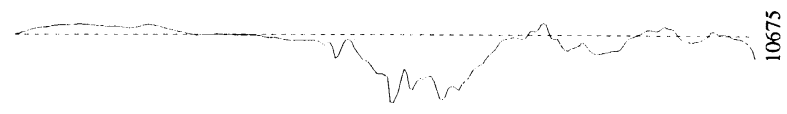

MUO

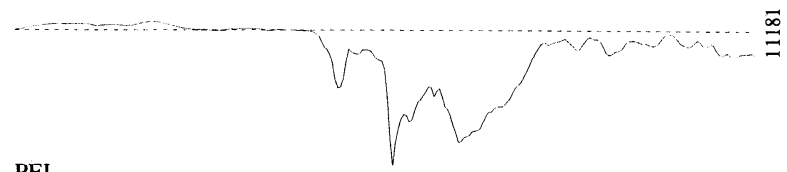

PEL

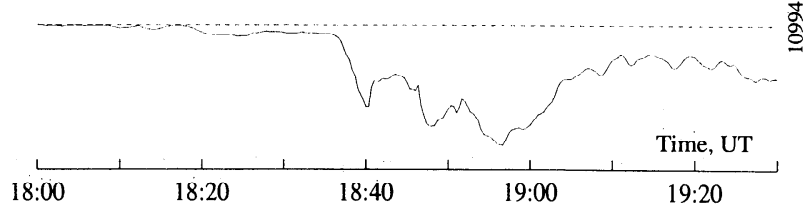

Figure 4a. $X$ components of magnetometer deflections seen by IMAGE magnctometer stations for 18001930 UT on the March 71991 . The scale next to the first trace applies to all the traces. A map showing the locations of the IMAGE magnetometer sites is given in Figure 3b.
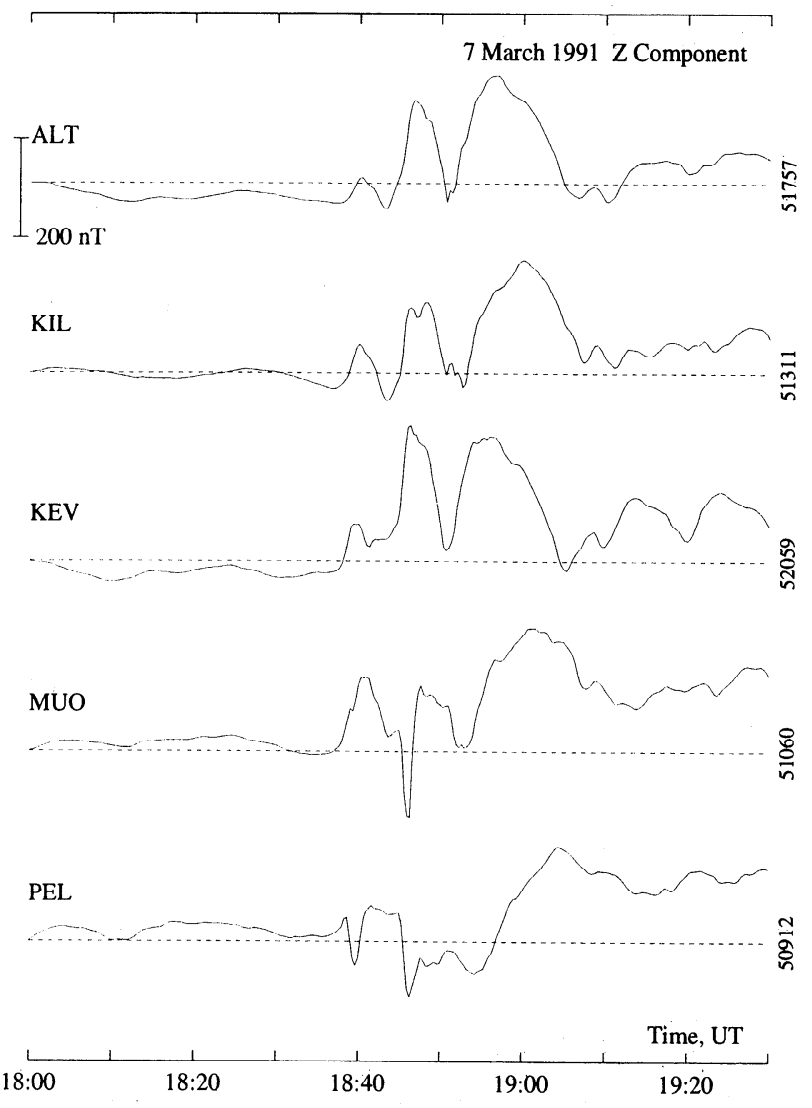

Figure 4b. $Z$ components of magnetometer deflections seen by IMAGE magnetometer stations for 1800 1930 UT on March 7 1991. The scale next to the first trace applies to all the traces. A map showing the locations of the IMAGE magnetometer sites is given in Figurc 3b.

the negative perturbation in $X$ and lasted till about 1856 UT, when the excursion in $X$ reached its maximum. $X$ then began to return to its preonset level, signalling the recovery phase. Very shortly before peak $X$, the deflection in the $Z$ component over Troms $\varnothing$ returned to its baseline value. Intense $\mathrm{Pi} 2$ activity, shown in Figure 5 and closely associated with the expansion phase of substorms, is visible in SAMNET data from 1837 UT until 1856 UT, confirming the onset time given above. Figure 6 shows that the IMF $Z$ component turned southward (at IMP 8) at about 1800 UT. We estimate from the spacecraft's position, the observed solar wind speed, and average locations of the bow shock and dayside magnetopause [Lockwood et al., 1989] that the change in IMF would have taken about 10 min to propagate to the Earth, indicating that open flux built up in the tail for about 30 min prior to substorm onset.

A negative perturbation in the magnetic $X$ component indicates that the magnetometer site is underneath the westward electrojet (Hall current). A positive excursion in the $Z$ component indicates that the electrojet causing the perturbation in the $X$ component is to the south of the site. Therefore EISCAT must have been poleward of an enhanced electrojet current at onset. Figure $4 \mathrm{~b}$, which shows the magnetic $Z$ component at 
7/3/91 Pi2

Day 66, 1991 : H Component : Filter (200, 40)

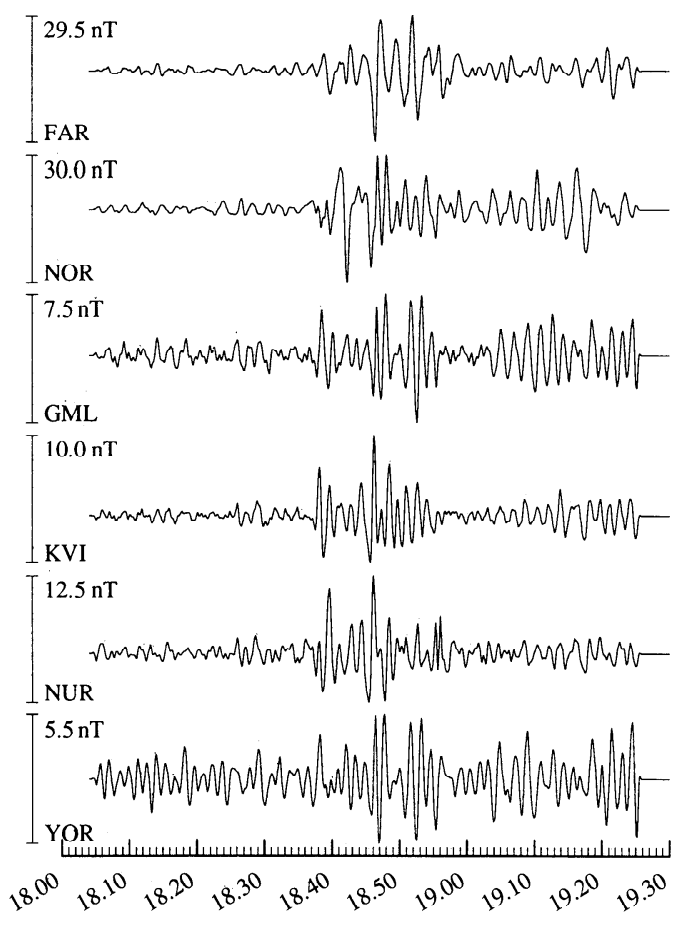

Figure 5. Intense $\mathrm{Pi} 2$ activity seen on March 7 in the $H$ components of SAMNET magnetometer data. Figure 3 a shows the locations of the SAMNET magnetometer stations.

the IMAGE magnetometer sites, helps to fix the latitude of the onset electrojet. We conclude that the center of the onset electrojet was more or less overhead of Pello, since there the excursion in $Z$ was nearly zero and the peak deflection in $X$ was observed there also. Pello has geomagnetic latitude $63.2^{\circ}, 3.4^{\circ}$ geomagnetically south of Troms $\varnothing$ (TRO; geomagnetic latitude $66.6^{\circ}$ ). This corresponds to a separation of roughly $350 \mathrm{~km}$. The $Z$ component of the IMAGE magnetograms (Figure $4 \mathrm{~b})$ as well as the $Z$ component of the Troms $\varnothing$ magnetogram (Figure 7) indicate that at least three electrojet intensifications occurred during the expansion phase. The first (as described above) was in the central meridian of the IMAGE chain, came at about 1838 UT, and was centred in latitude near Pello (PEL). The second, at $1844 \mathrm{UT}$, and the third, at $1851 \mathrm{UT}$, appear to have been centered at a latitude between that of Alta (ALT; geomagnctic latitude $66.28^{\circ}$ ) and that of Muonio (MUO; geomagnetic latitude $64.39^{\circ}$ ). The third and also most intense of the intensifications propagatcd westward, appearing at Kevo (KEV) at $1850 \mathrm{UT}$ and then at Kilpisjärvi (KIL) at around 1852 UT. SAMNET magnetometer data (not shown) also reveal this westward motion. From the peak $D$ deflections, the region of upward field-aligned current at the western end of this last and strongest electrojet is found to be at Nurmijärvi's (NUR) longitude at 1850, Kvistaberg's (KVI) and Nordli's (NOR) at 1852, and Glenmore's (GML) at 1858. Therefore before about 1850 , the main current wedge was to the east of the observation longitudes. However, when it did reach EISCAT's longitude, it was only $1.6^{\circ}$ (magnetic latitude) south of Troms $\varnothing$. That is, the main substorm current wedge appeared nearly $2^{\mathrm{O}}$ poleward of the onset electrojet which intensified over Pello, and not until 14 min after onset, at 21 MLT, wherc the obscrvations were made.

The analyzed EISCAT results arc presented in Figure 7 and Plate 1 . Figure 7 shows the ficld-perpendicular components of the flow, derived from the Doppler shifts measured at the three EISCAT sites. Magnetic data from the Troms $\varnothing$ Auroral Observatory are included for orientation. The flow had a southward component for all but eight of the 10-s integrations in the period shown between 1830 and 1930 UT. It was also generally westward, with short-lived eastward excursions occurring during a period of relatively weak zonal flow between 1844 and $1857 \mathrm{U}^{\prime} \mathrm{T}$. The onset of the substorm (1837 UT) was marked by a clear enhancement of the southward flow speed, which increased from $0.2 \mathrm{~km} \mathrm{~s}^{-1}$ to $0.8 \mathrm{~km} \mathrm{~s}^{-1}$. After onset, fast southward flow and increasing westward flow were in evidence until about $1841 \mathrm{UT}$, when the westward flow speed peaked at $1.5 \mathrm{~km} \mathrm{~s}^{-1}$. Prior to onset therefore, the flow was to the west of southwest, but at onset swung to the south of southwest. As the westward flow velocity increased, so the flow began to return to its original orientation. After 1841, the westward flow speed decayed to near-zero values, as described above, and the southward flow speed fluctuated around twice its preonset level (i.e. around $0.4 \mathrm{~km} \mathrm{~s}^{-1}$ ). Two isolated peaks in westward flow were observed at 1904 and 1907 UT, ard the field-perpendicular flow had a westward rather than

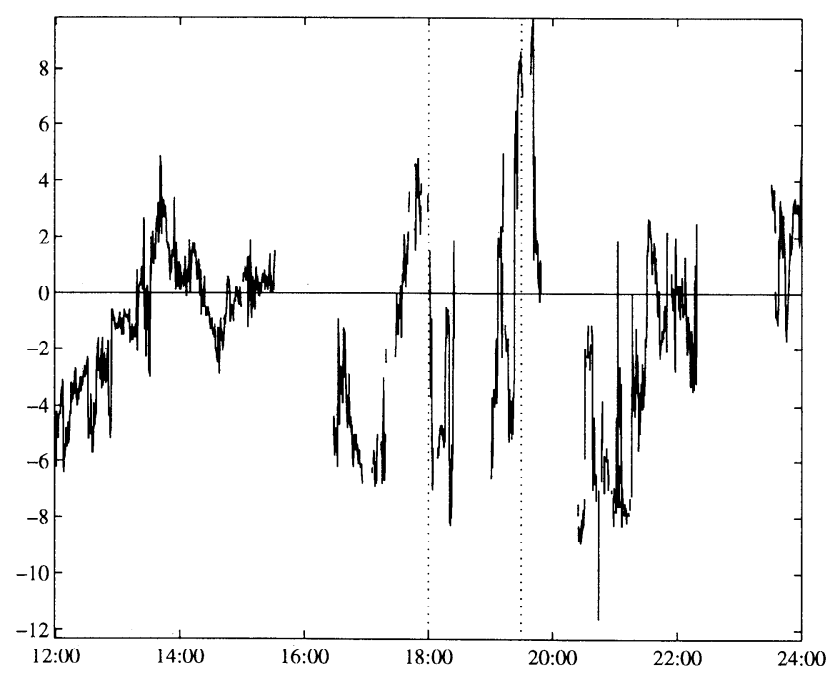

Figure 6. Interplanetary magnetic field measurements taken by the IMP 8 satellite at GSM coordinates $(29.7,12.3,-15.1) R_{E}$. Shown is the $Z$ coordinate in the GSM coordinate system. 

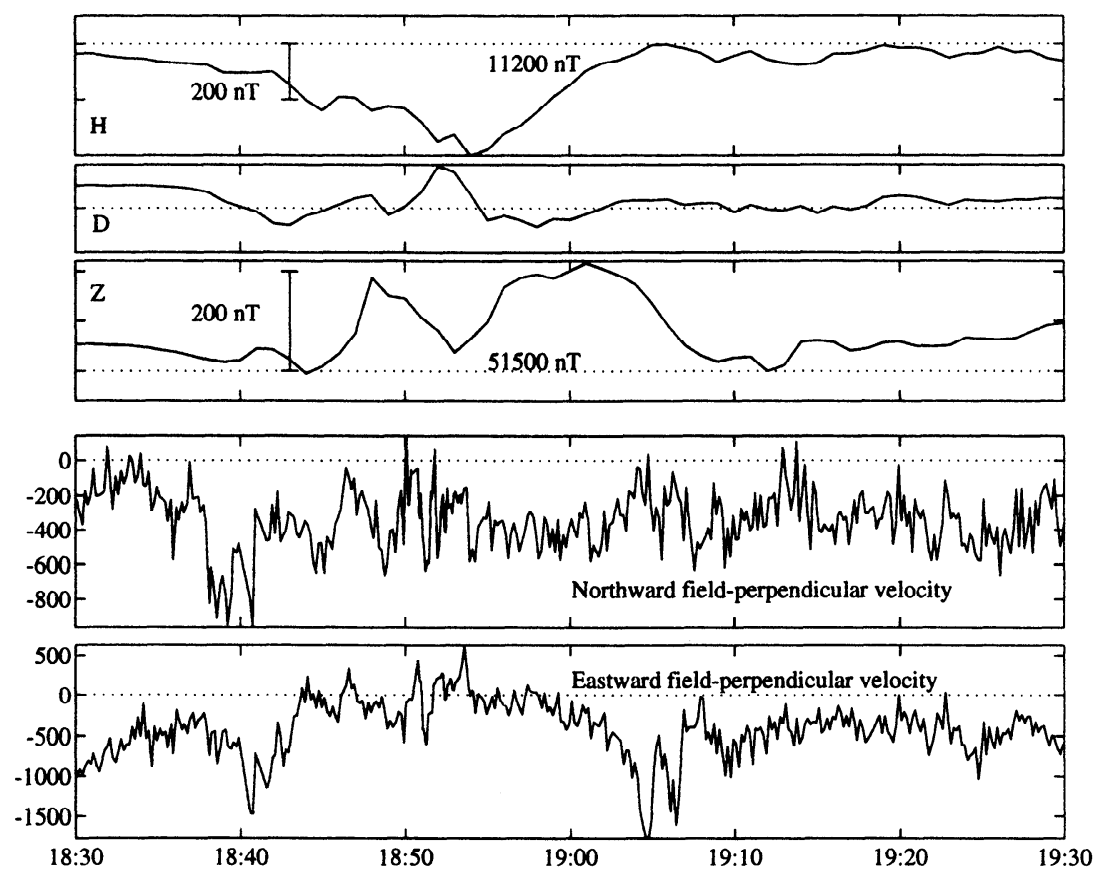

Figure 7. The bottom two panels show field-perpendicular velocity measured by EISCAT. For orientation, the $H, D$, and $Z$ magnetic field components measured at Troms $\varnothing$ are given on the same timescale in the first three panels. The substorm onset at 1837 UT was accompanied by a flow burst in which the southward component of velocity was initially somewhat more enhanced than the westward component. At 1840 UT, when arcs began to progress northward, the westward velocity over EISCAT almost tripled in magnitude. The flow burst finished at $1843 \mathrm{UT}$, roughly a minute before the auroral bulge passed over Troms $\varnothing$. This period is examined in more detail in Figure 10. The bursts of westward flow around 1905 UT accompanied the passage of southwestward drifting arcs over the radar in the late recovery phase. This second period is shown in more detail in Figure 11.

an eastward component until 1940, well after recovery from the first substorm.

The flow burst at onset can clearly be seen in the longpulse EISCA'T data (top 4 panels, Plate 1) as a rise in ion temperature $T_{i}$ between 1837 and 1841 (panel 3 ). This was not accompanied by a rise in the electron temperature $T_{e}$ (panel 2) and was such as to cause the temperature ratio $T_{e} / T_{i}$ (panel 4) to decrease to below 1. This means that the rise in ion temperature at onset was due to ion-neutral frictional heating and not to conduction of heat from the electron gas, thus confirming the existence of the flow burst seen in the velocity data (Figure 7). For most subsequent high $T_{i}$ values, the temperature ratio $T_{e} / T_{i}$ exceeded 1 , showing that they were, at least in part, caused by heating of the electron gas by ion-electron collisions, rather than solely by ionneutral frictional heating due to enhanced flow. The exceptions to this occurred at 1904, and 1907, when pronounced enhancements in westward flow occurred.

The top panel of Plate 1 shows the electron densities observed in the EISCAT long-pulse gates. These show clear enhancements in the $F$ region with sharp boundaries, particularly later in the period. The enhancements in electron density are probably polar cap patches convecting equatorward into the EISCAT beam, as re- ported by Lockwood and Carlson [1992] at this MLT. Also seen are enhancements in plasma density at low altitudes in the $E$ region. These are clearer in the multipulse data shown in the bottom panel of Plate 1. Several features can be seen in the multipulse data. First, near the time of substorm onset, there was a weak but marked increase in electron density which occurred simultaneously in all height gates (top panel). This can also be detected at the very lowest altitudes of the long-pulse data and reveals weak precipitation at onset. Much stronger precipitation was detected between 1848 and 1900 UT. A third feature consists of two seemingly dispersive electron density enhancements commencing at about 1905 and 1911 UT respectively.

Further evidence for precipitation comes from the luminosity observed in the EISCAT beam. This is shown as a function of time in Figure 8. The major features of this plot have been labeled A-F. The steplike increase in luminosity (A) corresponds to the weak increase in electron density observed by EISCAT at onset (see the bottom panel of Plate 1) and occurs at roughly the same time as the onset signatures at 1837. Between 1841 and 1845 , two further peaks in luminosity (B) were measured during the brief appearance of a weak electrojet overhead. EISCAT flow data show that the enhanced 
SP-UK-AUSU Tromsø UHF, Az 182.6, El 77.5

7th March 1991 18:30 - 19:30 UT

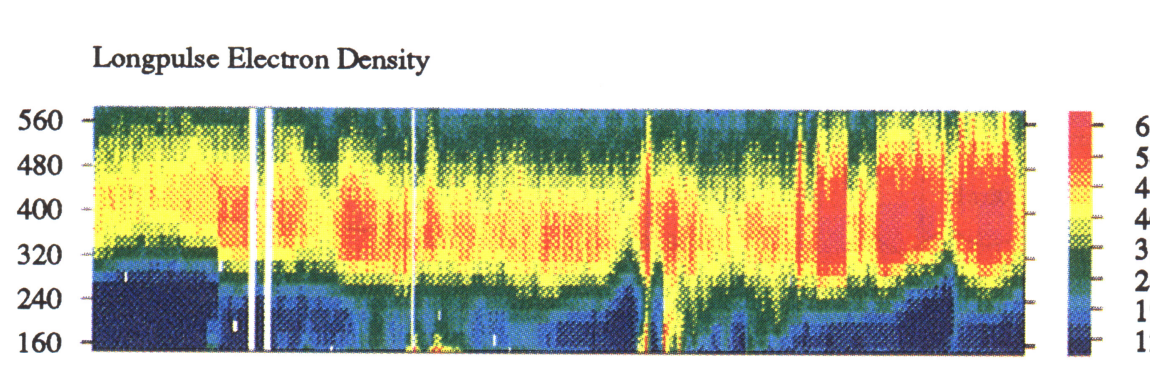

$\frac{\mathrm{Ne}}{10^{9} \mathrm{~m}^{-5}}$
$0^{-5}$
0
$\frac{\mathrm{Te}}{\mathrm{K}}$

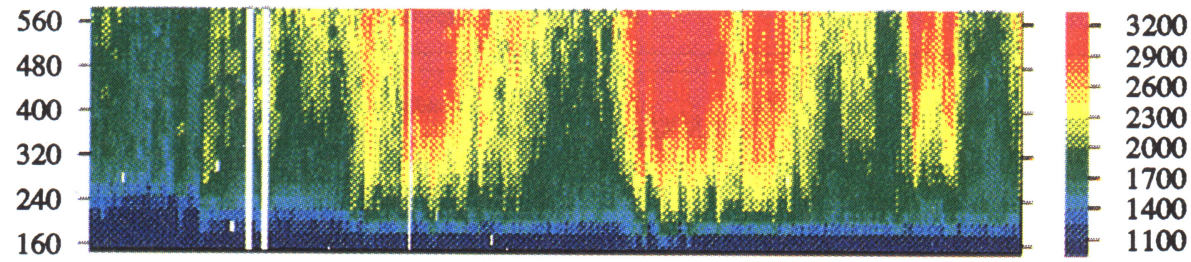

Longpulse Ion Temperature

\section{$\frac{T i}{K}$}

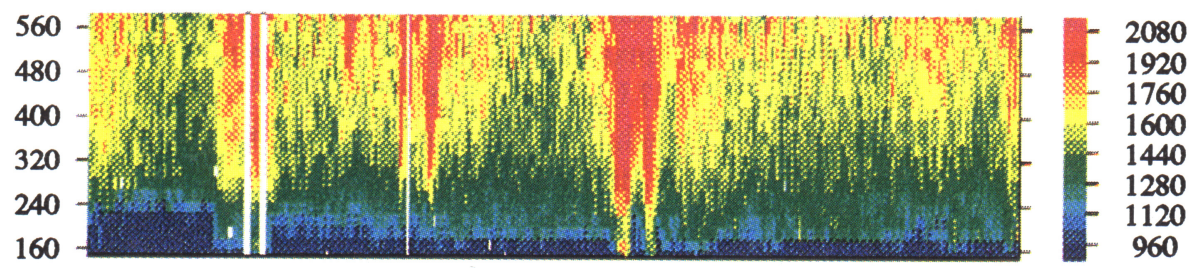

Longpulse Temperature Ratio

$\mathbf{T r}$
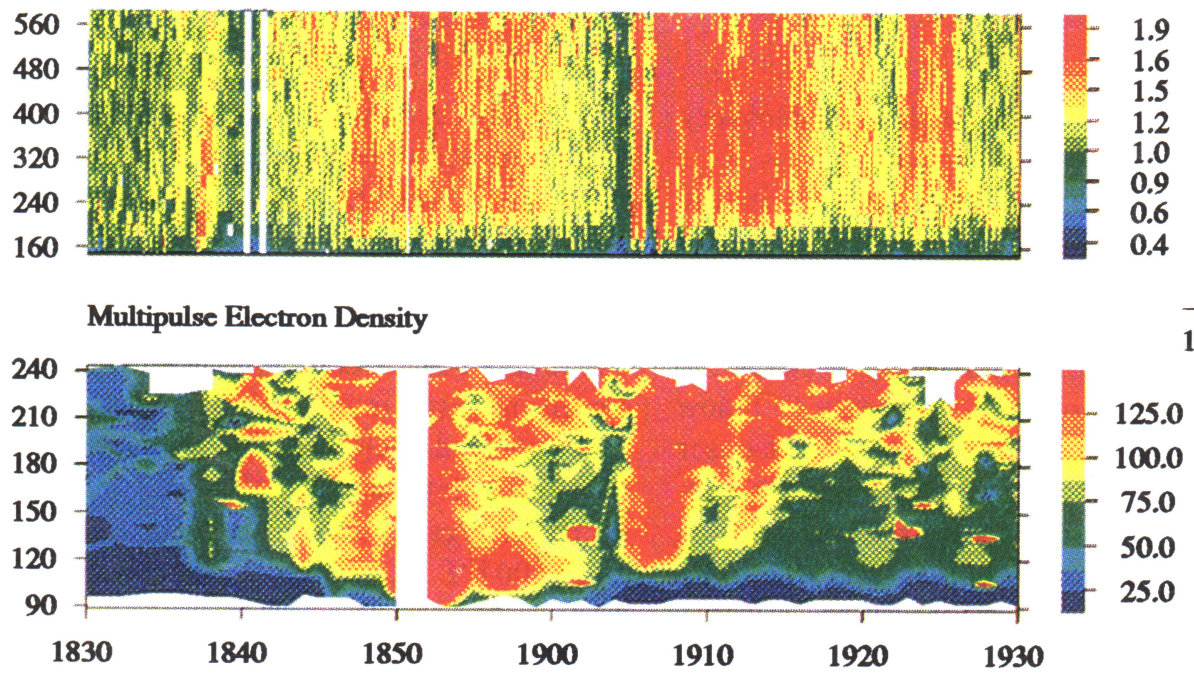

Plate 1. $F$ region long-pulse data (10-s resolution) and $E$ region multipulse data (1-min resolution) from the period 1830-1930 UT on March 7 1991. The top four panels show $F$ region electron density $n_{e}$, electron temperature $T_{e}$, ion temperature $T_{i}$, temperature ratio $T_{e} / T_{i}$, and the bottom panel shows corresponding $E$ region electron density data. Electron density enhancements at altitudes around $100 \mathrm{~km}$ clearly show the passage of arcs through the EISCAT beam.

westward flow which arose after onset was decaying during this time. A second steplike increase in luminosity (C) and a major peak in brightness at 1851 (D) were seen before the end of the expansion phase. Features
$\mathrm{C}$ and D have counterparts in the multipulse electron density data. During the time spanned by features $\mathrm{C}$ and $\mathrm{D}$ also, the field-perpendicular flow direction oscillated between southeast and southwest (Figure 7). Sub- 


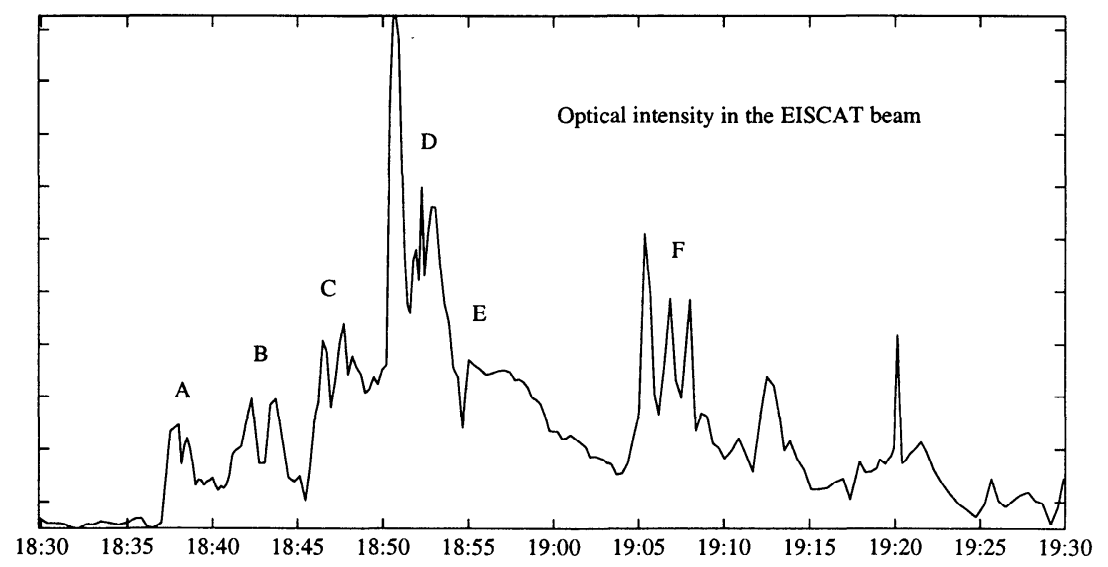

Figure 8. Optical intensity $(400-1150 \mathrm{~nm})$ in the EISCAT beam.

sequently, the optical intensity in the EISCAT beam decreased (E) before more arcs entered the beam between 1905 and 1908 (F), well into the recovery phase. These recovery phase arcs caused the dispersive electron density enhancements seen by EISCAT (bottom panel, Plate 1) and were preceded by two major bursts of westward flow and the conscquent ion tempcrature rises (Figure 7 and Plate 1).

The optical features seen in the EISCAT beam can only be understood by reference to all-sky camera data, presented here at selected times in Figure 9. A stable east-west arc developed near the northern edge of the camera's field of view at 1822 UT, with a second eastwest arc having formed north of that by about 1828 . Both arcs gradually drifted south (Figure 9a) and the more southerly of these drifted into EISCAT's field of view at 1837 U'I (Figure $9 \mathrm{~b}$ ), causing the small but distinct increase in brightness in the beam (A in Figure 8 ) and the rise in $E$ region density (see Plate 1 and Figure 10). The arrival of this arc in the EISCAT beam coincided with onset, and it was at this time also that an east-west arc became indirectly visible on the southern horizon, beyond the all-sky camera's direct field of view. The arc in the EISCAT beam went on to merge with the arc on the southern horizon, after the latter became visible at 1839 (Figure 9c). The southern arc then faded. Further arcs drifted into the EISCAT beam from the north and appeared by 1843 as the double east-west aligned arc of Figure 9d (see also B in Figure 8). The arc at the southern edge of the camera's field of view intensified again at 1845 , this time at a slightly more northerly location than before (Figure 9e), and immediately weak emission spread rapidly poleward (Figures $9 \mathrm{f}-9 \mathrm{~h})$, reaching the location of the initial northern arcs within a minute (Figure 9i), and passing through the EISCAT beam to cause the brightening of feature $\mathrm{C}$ in Figure 8 . The arc which then formed the northern edge of the bright area persisted, while the bright arc on the southern horizon faded out by 1848 . A westward travelling surge then travelled along the remaining northerly arc (Figures 9j-9l). The westward-travelling surge corresponds in latitude and timing to the expansion of the main current wedge westward and the electrojet seen over ALT/TRO by the SAMNET and IMAGE magnetometers. The arrival of the main surge head at Troms $\varnothing$ at 1851 gave rise to feature $\mathrm{D}$ in Figure 8. After this time, the most optical activity moved to the north of Troms $\varnothing$, but during the recovery phase, several arcs could be seen progressing southward from the northern edge of the camera's field of view, giving feature $\mathrm{F}$ in Figure 8.

Equatorward propagation of arcs has been observed both in the growth/early expansion phase and at the end of the recovery phase [Akasofu, 1964]. Persson et al., 1994] report similar features and conclude from order-of-magnitude calculations that the arcs drift with the same velocity as the local plasma. This conclusion, however, was based on a less than ideal EISCAT viewing geometry, and monostatic flow determination. Our EISCAT data provide an opportunity to test this result. Figures 10 and 11 show in detail data from the early expansion phase and the recovery phase respectively. In both figures, the top panel shows optical intensity at three positions in the sky, the second and third panels show the northward and eastward components of fieldperpendicular velocity, and the bottom panel shows the corresponding $E$ region electron density. The three positions at which the optical intensity has been measured are the position of the EISCAT beam and two positions $5^{\circ}$ geographically north and south of this. We see that the electron density associated with arcs peaks near $120 \mathrm{~km}$ and we assume that peak luminosity arises at this altitude also. Hence the two outlying sampling points are roughly $10 \mathrm{~km}$ to the north and south of the beam. Figure 10 covers features A, B, and C from Figure 8. The increase in luminosity at onset (feature $\mathrm{C}$ in Figure 8) occurs virtually simultaneously at all three positions, since this weak brightening convects slowly westward across the beam (Figure 9b). The next two southward drifting arcs (feature B in Figure 8) pass 


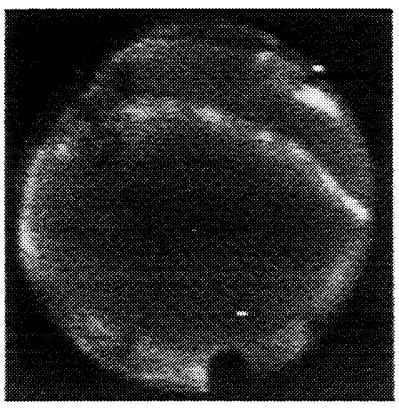

(a)

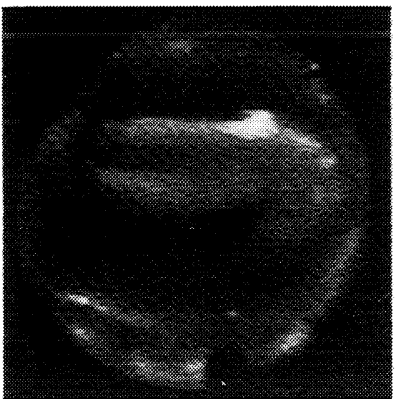

(d)

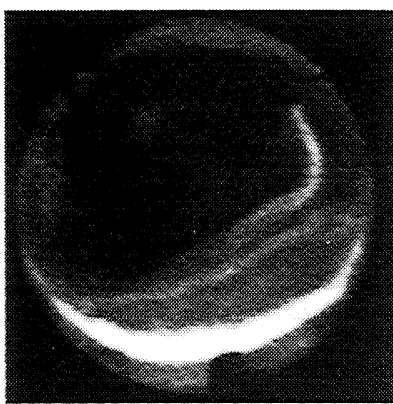

(g)

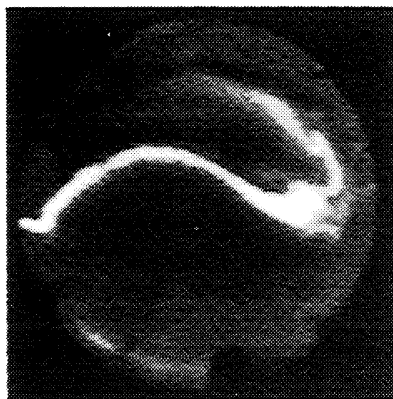

(j)

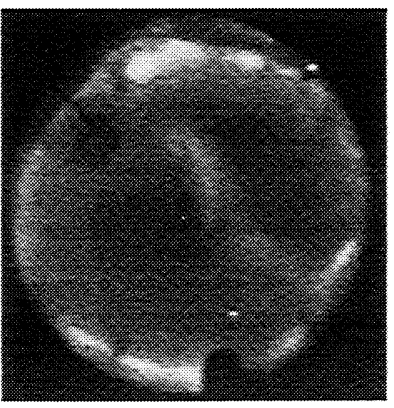

(b)

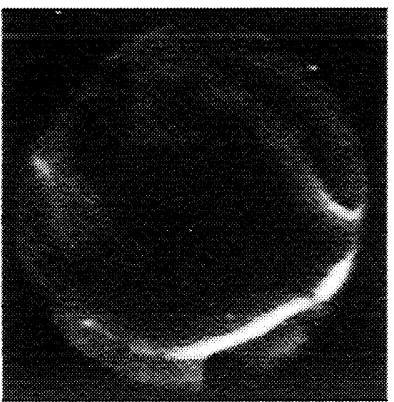

(e)

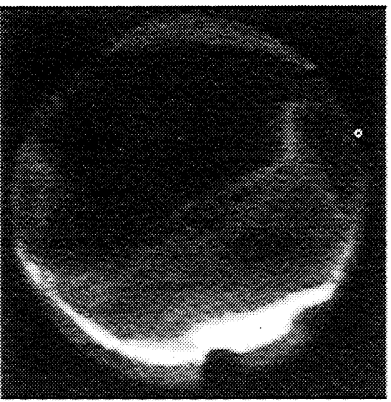

$($ h)

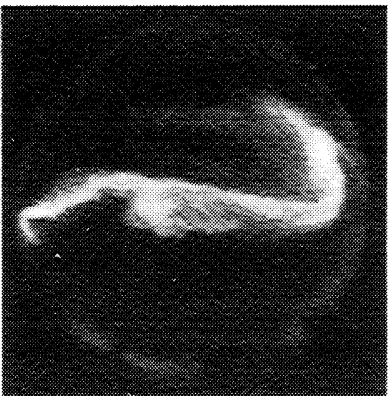

(k)

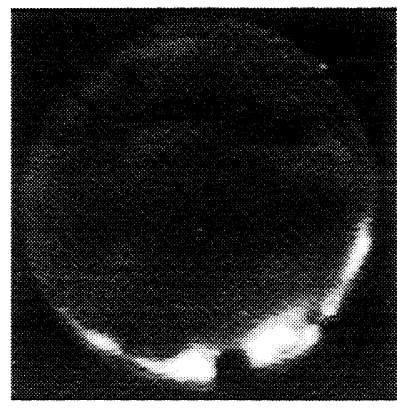

(c)

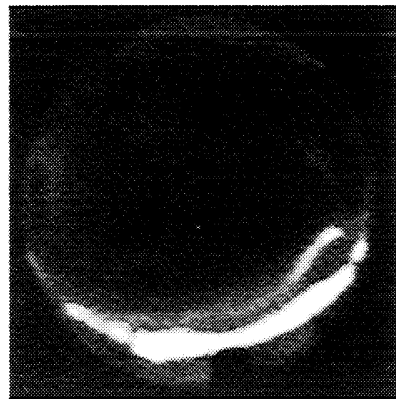

(5)

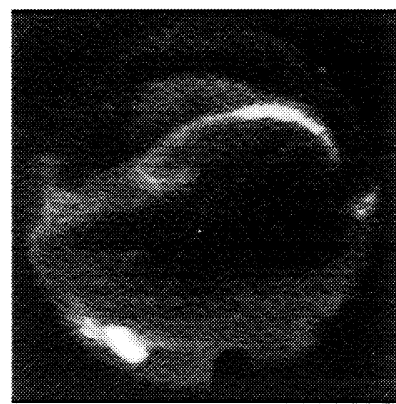

(i)

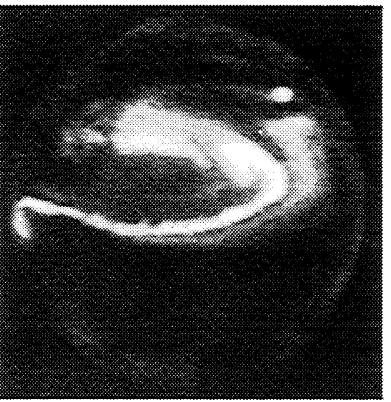

(1)

Figure 9. Selected all-sky camera frames showing the growth and expansion phase arcs. Geographic north is at the top of the picture, geographic south at the bottom, geographic west to the left, and geographic east to the right of it. 
Optical intensity (arbitrary units)

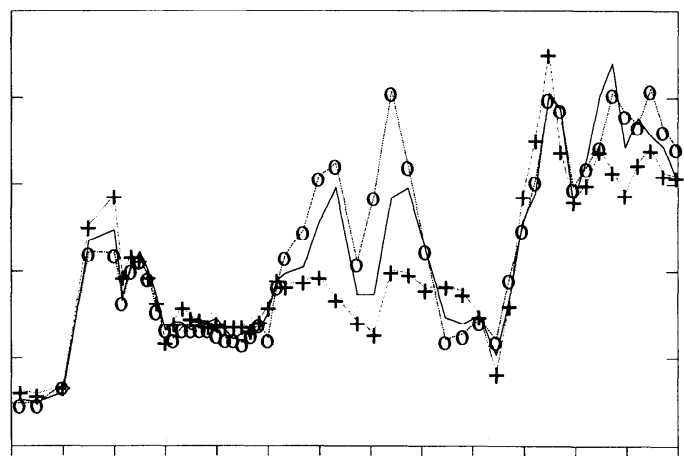

Northward velocity component $(\mathrm{m} / \mathrm{s})$

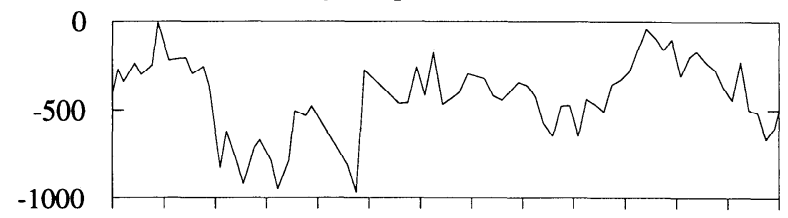

Eastward velocity component $(\mathrm{m} / \mathrm{s})$

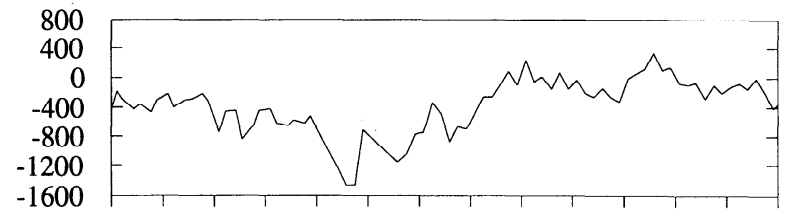

E-region electron density

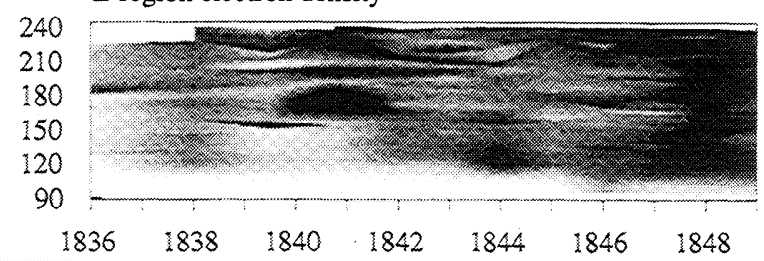

Figure 10. A composite plot showing measurements of optical intensity near the EISCAT beam, fieldperpendicular velocity data, and $E$ region electron density. In the optical intensity panel, the plain line shows optical intcnsity in the EISCAT beam itself, the line with circles shows the intensity $10 \mathrm{~km}$ to the (geographic) north, and the line with crosses shows intensity $10 \mathrm{~km}$ to the (geographic) south of the EISCAT beam. The period shown begins shortly before substorm onset at $1837 \mathrm{UT}$, and the top panel includes features A,B, and $\mathrm{C}$ from Figure 8 . In the bottom panel, higher electron density is represented by darker shading.

through the two more northerly sampling points (shown in Figure 10 by the lines with circles and the plain line respectively) but fade before reaching the southernmost sampling position (the line with crosses in Figure 10). The arcs are broadly east-west aligned (feature D in Figure 8), but only the delay between peaks at the two more northern sampling points can be used to estimate their southward motion. The first peak appears to travel the $10 \mathrm{~km}$ between the two sampling points in $10 \mathrm{~s}$ or less, giving an arc speed greater or equal to $1 \mathrm{kms}^{-1}$. The second peak takes roughly $20 \mathrm{~s}$ to cover the same distance, giving a speed of $0.5 \mathrm{~km} \mathrm{~s}^{-1}$. The images show that these two peaks keep a constant separation, and hence a mean time delay of 10 s seems appropriate, giving a mean speed of $1 \mathrm{~km} \mathrm{~s}^{-1}$. From panel 2 of Figure 10, we see that this estimate exceeds the observed plasma speed by a factor of somewhat more than 2. Figure 11 focuses on the southward moving east-west aligned arcs of the recovery phase (feature $\mathrm{F}$ in Figure 8). These arcs are measured to have been moving southwards at about $375 \pm 125 \mathrm{~ms}^{-1}$, while the local plasma flow speed observed at this time was $300 \pm 35 \mathrm{~ms}^{-1}$. The difference between arc and plasma speeds is found to be $75 \pm 160 \mathrm{~ms}^{-1}$. Note that the luminosity in the EISCAT beam has a three-peaked structure (Figure 11, top panel). All-sky camera images reveal that the first two of these peaks results from two southward drifting east-west aligned arcs. The third peak is a travelling fold of the second arc, which therefore appears at all three sampling positions simultaneously. With the proviso that not all arcs are strictly east-west aligned, which will slightly distort the estimated arc velocities, the comparisons do indicate that the growth and expansion phase arcs were moving southward faster than

Optical intensity (arbitrary units)

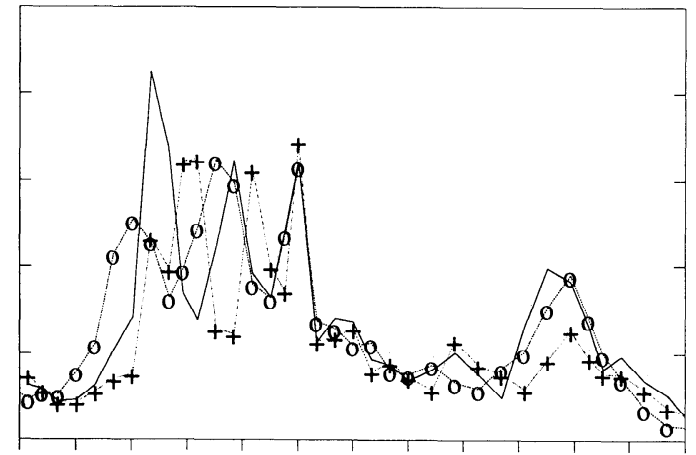

Northward velocity component $(\mathrm{m} / \mathrm{s})$

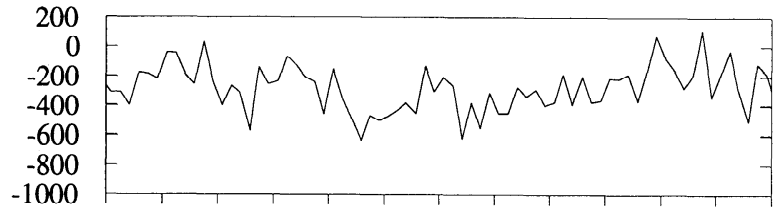

Eastward velocity component $(\mathrm{m} / \mathrm{s})$
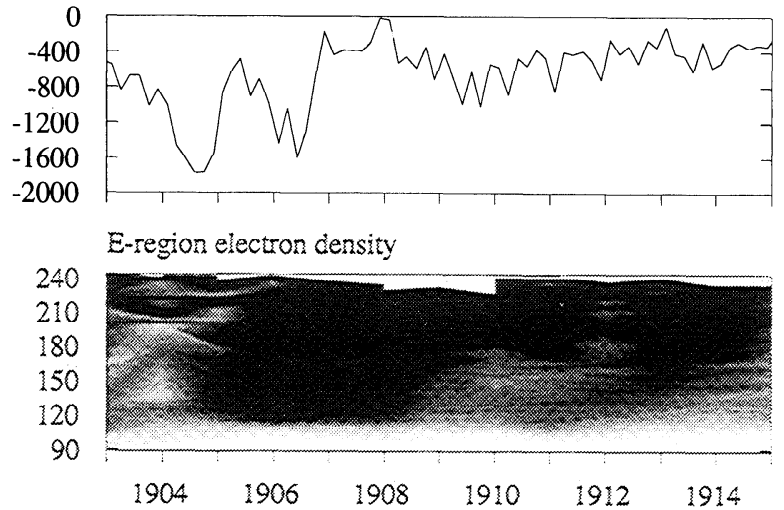

Figure 11. As for Figure 10, but showing the recovery phase arcs (feature F, Figure 8). 
the background plasma. Therefore the source of the precipitation was moving to lower invariant latitudes faster than the field lines. A similar conclusion was reached by Haerendel et al. [1993], although the arc velocity relative to the background plasma that they deduced lay between 30 and $180 \mathrm{~ms}^{-1}$. The southward moving arcs in the recovery phase, by contrast, appear to move at the local plasma flow speed only. The large uncertainties in these results arise because the arc motion was derived from just three points. We will present, in a future publication, a much more detailed analysis of arc phase motion which reduces these uncertainties greatly but produces the same overall result. The more detailed comparison is very lengthy and not required for the purposes of this paper.

\section{Discussion}

Morelli et al. [J. P. Morelli et al. (Radar observations of auroral zone flows during a multiple onset substorm, submitted to Annales Geophysicae, 1994, hereinafter referred to as Morelli et al., submitted maunscript)] have recently shown that during the expansion phase, the substorm electrojet is enhanced by a series of equatorward moving minielectrojets, which subsequently merge with the main electrojet. This corresponds to the behavior of the arcs and magnetometer deflections noted shortly after onset (Figure 8 , features A and B). Several interesting points emerge about these features from the current study. First, during their passage through the EISCAT field of view, the EISCAT flow data show no strong corresponding changes in the trends of the local plasma velocity (stable southward flow and declining westward flow). This implies that the effects seen in the magnetometer data are largely due to conductivity changes produced by the arcs. Second, these arcs were present to the north of EISCAT before onset, their behavior seemingly being unaffected by onset. From the velocity of the phase motion of thesc arcs, we find that they were probably moving south faster than the local plasma. In other words, their source was moving earthward across field lines. Possible explanations for this in terms of bouncing Alfvén waves have been given by Lysak [1986] and Haerendel et al. [1993]. As was mentioned above, more detailed analysis of this arc motion will be presented in a future publication.

The data reveal much about the relationship of the aurora to the open/closed field line boundary and the convection reversal boundary. From the start of EISCA' observations at $1800 \mathrm{UT}$, the flow was southwestward. The intensification of the electrojet at onset revealed it to be a westward Hall current electrojet (corresponding to roughly eastward convection) to the south of Troms $\varnothing$. Therefore by the time that onset happened, EISCAT was poleward of a convection reversal boundary. We infer from the presence of southward drifting arcs poleward of Troms $\varnothing$ at this time that this convection re- versal boundary was on closed field lines, but poleward of the intensifying electrojet. At onset, arcs were observed at zenith angles of roughly $65^{\circ}$ to the north of Troms $\varnothing$. If we assume that such arcs are produced only on closed field lines, this places the open/closed field line boundary more than $260 \mathrm{~km}$ to the north of Troms $\varnothing$ (for an assumed emission altitude of $120 \mathrm{~km}$ ). Conversely, the IMAGE data show the electrojet center to have been approximately $350 \mathrm{~km}$ south of the radar site at this time. Consequently, we infer that onset was at least $600 \mathrm{~km}$ equatorward of the open/closed field line boundary (roughly $5.5^{\circ}$ of invariant latitude). The EISCAT flow data therefore define the convection reversal boundary to be between $260 \mathrm{~km}$ and $600 \mathrm{~km}$ equatorward of the open/closed ficld line boundary. The flows at EISCAT were weak when the western end of the main substorm wedge (upward field-aligned current and an auroral surge) passed over the site, and the westward field-aligned velocity component reversed direction to the east at times. We infer that that the convection reversal boundary had migrated north at this time, closer to the open/closed field line boundary. The westward travelling surge established a new westward electrojet (consistent with the eastward flow seen by FISCAT at this time) to the north of the one that intensified at onset. After the burst following onset, the equatorward flow speed remains relatively constant around $0.4 \mathrm{kms}^{-1}$ throughout.

The major variations in field-perpendicular flow took place immediately after onset at 1840 and during the recovery phase (1905-1908). We discuss these in turn. In the first of these, enhanced equatorward flow was followed by enhanced westward flow. The enhancement of westward flow came immediately before an arc appeared to the north of the EISCAT beam (see Figure 10). In the NENL model, this flow burst feature could be explained as the response of nightside flows to the closure of open flux at the NENL, after a plasmoid has been pinched off [Lockwood ct al., 1990]. However, for this to be the casc requircs reconnection of opcn flux to start at onset. While in the Kiruna model, reconnection at the NENL and onset may by chance be simultaneous processes [Reeves, 1993], an alternative explanation is that the enhanced flow observed was the result of a conductivity enhancement southeast of Troms $\varnothing$. If the early expansion phase does not correspond to a period of open flux closure at the NENL and the flux transfer caused by the distant neutral line remains constant, then the distribution of potential around the open/closed field line boundary will not have been altered by the occurrence of onset. However, a region of high conductivity will have been produced to the south of the open/closed field line boundary by the onset process itself, and flow streamlines will tend to avoid it [Morelli et al., submitted maunscript] i.e., "onset" as such will cause a rearrangement of the existing flow pattern in the part of the ionosphere that it maps to. A region of enhanced conductivity to the southeast would cause an increase 
of both the southward and westward field-perpendicular velocity components, as streamlines avoided the highconductivity region by passing to the north and west of it. Note that this is a "mechanistic" description of this effect. A fully equivalent description is that the electric field is reduced in regions of high conductivity due to polarization effects. If then the high-conductivity region expanded west toward EISCAT's longitude, the direction of the enhanced flow would swing westward, which was observed. When the main auroral bulge expanded over the radar at 1815 , both velocity components at EISCAT decayed in magnitude, confirming that the luminous, high-conductivity region was one of relatively slow flow, i.e., streamlines did indeed tend to avoid it. The second set of flow bursts which came during the recovery phase (Figure 11) occurred in association with the passage of arcs through the beam. Such flow signatures, in the form of high electric fields preceding arcs, have been observed before using EISCA'I data [Williams et al., 1990, Opgenoorth et al., 1990]. In the same vein, Wescott et al. [1969] found in barium release experiments that ionospheric plasma generally moved tangentially ahead of arcs. Both these findings support the idea that flow streamlines avoid the high conductivity region produced by an arc. A closer examination of Figure 11 reveals that the seemingly dispersive precipitation signature (bottom panel) may be due to the combined effects of two arcs.

During the period of low flow (1845-1855), EISCAT seemed to repeatedly cross a convection reversal boundary, which on occasion moved poleward of Troms $\varnothing$, leading to south-eastward flow at Troms $\varnothing$. Note that the sense of the dominant electrojet was not altered by the change in flow direction from southwest to southeast, as can be seen from the fact that the bay in the magnetic $H$ component at Troms $\varnothing$ rcmained ncgative throughout. Therefore EISCAT crossed a convection flow boundary, rather than changing to a different flow cell. That the electrojet was then overhead at Troms $\varnothing$ is confirmed by the return of the local $Z$ component of the magnetic deflection to zero (Figure 4b). Figures $4 \mathrm{a}, 4 \mathrm{~b}$, and 7 show that the electric field was westward, but there was a large positive perturbation in $Z$ at Troms $\varnothing$, showing that the magnetometer was responding to an electrojet to the south and not to the local electric field at 'Iroms $\varnothing$. 'This is confirmed by inspection of the latitudinal profile of the $X$ deflection at these times, which shows peaks near Muonio, considerably to the south of Troms $\varnothing$. The southward flow burst which took place in the early expansion phase is the only signature which could be associated with a burst of open field line closure, the southward flow remaining relatively constant throughout the remainder of the expansion phase and the recovery phase. However, we believe that this feature may, in reality, be due to conductivity enhancements at onset. Open flux accumulated in the tail during substorm growth phases must at some stage (for average substorms) be destroyed again. Lockwood and
Cowley [1992] argue from convection patterns derived by magnetogram inversion, that open flux is destroyed about 20-30 min after onset (at least for the CDAW-6 substorm on March 22 1979, which they studied in detail). This would place open flux closure in the recovery phase, and possibly in the late expansion phase, consistent with the Kiruna conjecture (Figure 2). There is no evidence here for such a long delay.

A key point to remember about these observations is that the main onset of the substorm was to the east of the observations and that the main current wedge only spread west over the field of view at $1851 \mathrm{UT}, 14 \mathrm{~min}$ later. Therefore they do not resolve the debate about the NENL and Kiruna conjecture models as far as the center of the tail (GSE $Y=0$ ) is concerned. However, they do tell us about what happened in the duskside of the tail, which maps to the observed region of the ionosphere near 2100 MLT.

At onset, there was a clear optical enhancement off to the south of the camera's field of view, and it peaked at 1839. We infer that it occurred on closed field lines, because it was equatorward of the southward moving arcs also seen at that time. The brightening (and considerable activity) was also accompanied by the enhancement of a westward electrojet over Pello, and occurred simultaneously across the southern part of the camera's field of view. Hence it would appear to correspond to a current disruption taking place across the whole of the corresponding part of the duskside of the central plasma sheet. This initial brightening then faded (at 1843 ) and intensified again (at 1845) as it moved poleward, which would correspond to a tailward drift of the disruption region. The main luminosity stayed in the south, but its poleward edge expanded poleward very rapidly (crossing the radar beam at a least $4 \mathrm{~km} \mathrm{~s}^{-1}$; see Figure 10 and feature $\mathrm{C}$ of Figure 8), moving roughly $550 \mathrm{~km}$ in about $2 \mathrm{~min}$. By 1847 , it had reached the location at which the southward moving arcs formed, and this could be interpreted as the open/closed field line boundary. The arc motion would then correspond to a very rapid tailward expansion of the source inside a region on closed field lines. The earliest that current disruption can have reached the open/closed field line boundary thus is 1847, a full 10 min after onset, and means that at the longitudes at which we observed, a plasmoid was not pinched off until this time, although this is not to say that the plasmoid was not pinched off nearer the center of the tail at some earlier time.

Given that both the NENL model and the Kiruna version predict that onset takes place on closed field lines, a key difference between them that can be tested is the time that it takes to pinch off the plasmoid [Lester et al., 1995]. In the case of the substorm described here, this time appears to be $10 \mathrm{~min}$, located as the instruments were near 2100 MLT. Nearer midnight, it may or may not have been less; we cannot tell. The delay of at least 10 min derived here is more consistent with the Kiruna conjecture than the NENL model, but the pos- 
sibility remains that the answer will depend upon which MLT one considers, i.e., how close one is to the center of the plasmoid. This longitudinal difference could provide a bridge between the Kiruna and classical NENL models. A near-Earth neutral line could have formed at onset somewhere to the east of our observations, and this could have rapidly pinched off a plasmoid at that local time, contributing to the flow burst seen by EISCAT and causing tail flux to begin to decay from soon after onset, so causing decay of the lobe field [McPherron et al., 1993]. However, we know that the onset features seen at 2100 MIT were on closed field lines and that the plasmoid at this location took considerably longer to be pinched off, so the Kiruna model is more appropriate at this MLT.

Another interesting feature of the data presented here is that when the current disruption has expanded tailward such that the corresponding arc has reached the inferred open/closed field line boundary, a great intensification appears to propagate along it from the center of the tail out to the flanks of the magnetosphere, giving the westward travelling surge. As this moved over the longitude of the ground-based instruments at 1851, they entered the main substorm current wedge for the first time. One possibility may be that the initial current disruptions were in near-Earth tail at $X \sim-8 R_{E}$ (in the part of the tail mapping to 2100 MLT in the ionosphere) and did not involvc rcconnection, but that this spread downtail to $X \sim-19 R_{E}$, where the NENL formod, and then spread rapidly azimuthally. This is only conjecture but would provide a reason for why the main substorm electrojet was more severe than the earlier disruptions which probably originated closer to the Earth.

Finally, there is one more test that can be made with this data to differentiate between the effects of the classic NENL and Kiruna models. It concerns the equatorward motion of the recovery phase arcs. In both models, the main aurora lies near the open/closed field line boundary at the start of the recovery phase. In the NENL model, the most poleward recovery phase arc is always on the open/closed boundary and its subsequent equatorward motion reflects the continued addition of open flux to the polar cap by magnetopause reconnection and the polar cap's resulting expansion. In this case, the arc and the plasma should move together if no tail reconnection is taking place locally (i.e., the boundary is "adiaroic"; see discussion by Lockwood and Cowley [1992]). Alternatively plasma flow would be faster than arc motion if tail reconnection continued to take place on the nightside at the local MLT. Therefore for the NENL model, this arc would migrate equatorward as the polar cap expanded and would move at the same spccd as, or slower than, the background plasma. On the other hand, this arc must move faster than the open/closed field line boundary in the Kiruna model if it is to lie equatorward of the boundary by the onset of the next substorm. By this time, going by the sub- storm studied here, the arc should be roughly $600 \mathrm{~km}$ equatorward of the open/closed field line boundary, a gap which must grow during the recovery and growth phases (i.e., in the space of roughly 1 hour) giving the arc a mean speed of $167 \mathrm{~m} \mathrm{~s}^{-1}$ in the rest frame of the boundary. Hence the arc speed equatorwards may exceed that of the local plasma by something of the order of $150 \mathrm{~m} \mathrm{~s}^{-1}$, averaged over the recovery and subsequent growth phase. If tail reconnection persists at the local MLT, then the equatorward flow of plasma may cause the velocity of the arc relative to the background plasma to be lessened or even made negative. Nevertheless, we can conclude that an observation of a recovery phase arc moving equatorward faster than the background plasma by a speed of up to about $150 \mathrm{~ms}^{-1}$ is consistent with the Kiruna model, but inconsistent with the classical NENL model. The southward moving arcs observed in the late growth/early expansion phase move at phase speeds which do appear to exceed the local plasma flow. From the dala presented here, we cannot definitely state that this was true of the recovery phase arcs, which we find to have been moving at $75 \pm 160 \mathrm{~m} \mathrm{~s}^{-1}$ relative to the background, but nor is our result inconsistent with the prediction of the Kiruna model of an excess arc speed somewhere between 0 and $150 \mathrm{~ms}^{-1}$.

\section{Conclusions}

In conclusion, the observations that we present support the Kiruna model of substorms in that they show that Troms $\varnothing$, at the time of onset, was poleward of an enhanced electrojet, poleward of the origin of substorm expansion, and poleward of a convection reversal boundary, yet was seemingly equatorward of the open/closed field line boundary since auroral features were observed to the north. If the initial current disruption was not due to an near-Earth neutral line, then there was at least a 10 min delay before open flux was reconnected at the longitude of observation (2100 MLT). This location was only engulfed by the main substorm current wedge relatively late in the substorm's evolution (14 min after onset). There is the possibility that difference betwecn the behavior at the various longitudes may mean that both models apply, the "classical" NENL describing the evolution nearer the center of the tail, and the Kiruna conjecture applying at 2100 MLT. We find some evidence that the phase motion of equatorward drifting arcs in the late growth/early expansion phase exceeds the local plasma flow. Should the velocity of the recovery phase arcs exceed that of the background, this would be inconsistent with the NENL model but expected for the Kiruna model. Unfortunately, the experimental uncertainties in this determination do not allow in our case for us to discriminate between the two models on this basis.

Acknowledgments. The authors wish to thank Ron Lepping of the Goddard Space Flight Center for supplying 
IMP 8 data via the World Data Centre C1 at R.A.L. We also wish to thank Truls Hansen for the Troms $\varnothing$ magnetometer data, and the director and staff of the EISCAT scientific association. EISCAT is supported by the Science and Engineering Research Council (U.K.), Norges Almenvitenskapelige Forskningsråd (Norway), the Naturvetenskapalige Forskningsråd (Sweden), the Suomen Akatemia (Finland), the Max-Planck Gesellschaft (Germany), and the Centre National de la Recherche Scientifiquc (France).

'The editor thanks Hermann J. Opgenoorth and a second referee for their assistance in evaluating this paper.

\section{References}

Akasofu, S., The development of the auroral substorm, Planet. Space Sci., 12, 273, 1964.

Baker, D.N., T. Pulkkinen, R. L. McPherron, J. D. Craven, L. A. Frank, R. D. Elphinstone, J. S. Murphree, J. F. Fennel, R. E. Lopez, and T. Nagai, CDAW 9 analysis of magnetospheric events on May 3, 1986, J. Geophys. Res., 98, 3815-3834, 1993.

Baumjohann, W., G. Paschmann, T. Nagai and H. Lühr, Superimposed epoch analysis of the substorm plasma sheet, J. Geophys. Res., 96, 11,605-11,608, 1991.

Baumjohann, W., G. Paschmann and T. Nagai, Thinning and expansion of the substorm plasma sheet, J. Geophys. Res., 97, 17,173-17,175, 1992.

Birn, J. and M. Hesse, MHD simulations of magnetic reconnection, J. Geophys. Res., 96, 23-24, 1991a.

Birn, J. and M. Hesse, The substorm current wedge and field-aligned currents in MHD simulations of magnetotail reconnection, J. Geophys. Res., 96, 1611-1618, 1991b.

Coles, S., An automatic auroral imaging system, PhD Thesis, Sussex University, Falmer, England, 1992.

Elphinstone, R. D. and D. J. Hearn, The auroral distribution and its relation to magnetospheric processes, Adv. Space Sci., 13(4), 17-27, 1993.

Elphinstone, R. D., J. S. Murphree, D. J. Hearn, L. L. Cogger, P. T. Newell and H. Vo, Viking observations of the UV dayside aurora and their relationship to DMSP particle boundary definitions, Ann. Geophys., 10, 815-826, 19.91.

Feldstein, Y. I and Y. I. Galperin, An alternative interpretation of auroral precipitation and luminosity observations from the DE, DMSP, AUREOL and Viking satellites in terms of their mapping to the nightside magnetosphere, J. Atmos. Terr. Phys., 55, 105-121, 1993.

Galperin, Y. I. and Y. I. Feldstein, Auroral luminosity and its relationship to magnetospheric plasma domains, in $\mathrm{Au}$ roral Physics, edited by C-I. Meng, M. J. Rycroft, and L. A. Frank, pp. 207-219, Cambridge University Press, New York, 1991.

Haerendel, G., S. Buchert, C. Ta. Hoz, B. Raaf and E. Rieger, On the proper motion of auroral arcs, J. Geophys. Res., 98, 6087-6099, 1993.

Hones, E. W. Jr., The magnetotail: Its generation and dissipation, in Physics of Solar Planetary Environments, edited by D. J. Williams, pp. 559-571, AGU, Washington, D.C., 1976.

Kennel, C. F., The Kiruna conjecture: The strong version, in Substorms 1: Proceedings of the 1st international Conference on Substorms, ICS-1, Eur. Space Agency Special Publ. 335, 599-601, 1992.

Lester, M., M. Lockwood, T. K. Yeoman, S. W. H. Cowley, H. Lühr, R. J. Bunting and C. J. Farrugia, The response of ionospheric convection in the polar cap to substorm activity, Ann. Geophys., in press 1995.

Lockwood, M. and H. C. Carlson Jr., Production of polar cap electron density patches by transient magnetopause reconnection, Geophys. Res. Lett., 19, 1731-1734, 1992.

Lockwood, M. and S. W. II. Cowley, Ionospheric convection and the substorm cycle, in Substorms 1: Proceedings of the 1st International Conference on Substorms, ICS-1, Eur. Space Agency Special Publ. 335, 99-109, 1992.

Lockwood, M., P. E. Sandholt, S. W. H. Cowley and T. Oguti, Interplanetary magnetic field control of dayside auroral activity and the transfer of momentum across the dayside magnetopause, Planet. Space Sci., 37, 1347-1365, 1989.

Lockwood, M., S. W. H. Cowley and M. P. Freeman, The excitation of plasma convection in the high-latitude ionosphere, J. Geophys. Res., 95, 7961-7971, 1990.

Lopez, R. E., H. E. Spence and C-I. Meng, DMSP F7 observations of a substorm field-aligned current, J. Geophys. Res., 96, 19409-19415, 1991.

Lopez, R. E., H. E. Spence and C-I. Meng, Substorm aurorae and their connection to the inner magnetosphere, $J$. Gcomag. Gcoclcctr., 44, 1251 1260, 1992.

Lopez, R. E., H. E. J. Koskinen, T. Pulkkinen, T. Bösinger, R. W. McEntire, and T. A. Potemra, Simultaneous observation of the poleward expansion of substorm electrojet activity and the tailward expansion of current sheet disruption in the near-Earth magnetotail, J. Geophys. Res., 98, 9285-9295, 1993.

Lühr, H., S. Thürey and N. Klöcker, The EISCAT magnetometer cross: Operational aspects, first results, Geophys. Surv., 6, 305-315, 1984

Lysak, R. L., Coupling of the dynamic ionosphere to auroral flux tubes, J. Geophys. Res., 91, 7047-7056, 1986.

McPherron, R. L., V. Angelopoulos, D. N. Baker and E. W. Hones Jr., Is there a near-Earth neutral line?, Adv. Space Sci., 13,(4) 173-186, 1993.

Moldwin, M. B. and W. J. Hughes, On the formation and evolution of plasmoids: A survey of ISEE 3 geotail data, J. Geophys. Res., 97, 19259-19282, 1992.

Moldwin, M. B. and W. J. Hughes, Geomagnetic substorm association of plasmoids, J. Geophys. Res., 98, 81-88, 1993.

Murphree, J. S. and L. L. Cogger, Observations of substorm onset, in Substorms 1: Proceedings of the 1st International Conference on Substorms, ICS-1, Eur. Space Agency Special Publ. 335, 207-212, 1992.

Murphree, J. S., R. D. Elphinstone, M. G. Henderson and L. L. Cogger and D. J. Hearn, Interpretation of optical substorm onset observations, J. Atmos. Terr. Phys., 55, 1159-1170, 1993.

Ohtani, S., S. Kokobun and C. T. Russell, Radial expansion of the tail current disruption: a new approach to the substorm onset region, I. Atmos. Terr. Phys., 97, 3129-3136, $1992 \mathrm{a}$.

Ohtani, S., K. Takahashi, L. J. Zenetti, T. A. Potcmra, and R. W. McEntire, Initial signatures of magnetic field and energetic particle fluxes at tail reconfiguration: Explosive growth phase, J. Geophys. Res., 97, 19,311-19,324, $1992 \mathrm{~b}$.

Opgenoorth, H., I. Häggström, P. J. S. Williams, and G. O. L. Jones, Regions of strongly enhanced electric fields adjacent to auroral arcs, J. Atmos. Terr. Phys., 52, 449$458,1990$.

Owen, C. J. and J. A. Slavin, Energetic tail events associated with travelling compression regions, in Substorms 1: Proceedings of the 1st International Conference on Substorms, ICS-1, Eur. Space Agency Spccial Publ. 335, 1443-1446, 1992.

Persson, M. A. L. et al., Near-Earth substorm onset: A coordinated study, Geophys. Res. Lett., ,21 1875-1878, 1994.

Pulkkinen, T., A study of magnetic field and current config- 
urations in the magnetotail at the time of substorm onset, Planet. Space Sci.39, 833-845, 1991.

Pulkkinen, T., D. N. Baker, D. H. Fairfield, R. J. Pellinen, J. S. Murphree, R. D. Elphinstone, R. L. McPherron, J. F. Fennel, R. E. Lopez and T. Nagai, Modelling the growth phase of a substorm using the Tysganenko model and multi-spacecraft observations; CDAW 9, Geophys. Res. Lett., 18, 1963-1966, 1991a.

Pulkkinen, T., H. E. J. Koskinen and R. J. Pellinen, Mapping of auroral arcs during the substorm growth phase, J. Geophys. Res., 96, 21,087-21,094, 1991b.

Reeves, G. D. , Multiple substorm injections and the new substorm paradigm: Interpretation of the CDAW 7 substorm, Adv. Space Sci.13(4), 213-216, 1993.

Samson, J. C., L. R. Lyons, P. T. Newell, F. Creutzberg and $\mathrm{B}$. $\mathrm{Xu}$, Proton aurora and substorm intensifications, Geophys. Res. Letl., 19, 2167-2170, 1992a.

Samson, J. C., D. D. Wallis, T. J. Hughes, F. Creutzberg, J. M. Ruohoniemi and R. A. Greenwald, Substorm intensifications and field line resonances in the nightside magnetosphere, J. Geophys. Res., 97, 8495-8518, $1992 \mathrm{~b}$.

Sholer, M. and R. Hautz, On acceleration of plasmoids in MHD simulations of magnetotail reconnection, J. Geophys. Res., 96, 3581-3588, 1991.

Slavin, J. A, E. L. Smith, D. N. Mazur, T. Baker, H. J. Iyemori, H. J. Singer and E. W. Greenstadt, Plasmoid and $\mathrm{TCR}$ observations during an extended interval of substorm activity, Geophys. Res. Lett., 19, 825-828, 1992.

Walker, R. J, T. Ogino, M. Ashour-Abdalla and J. Raeder, A global MHD simulation of magnetospheric dynamics when the IMF is southward: Mapping to the auroral zone, in Substorms 1: Proceedings of the 1st International Conference on Substorms, ICS-1, Eur. Space Agency Special Publ. 335, 571-576, 1992.
Wescott, E. M., J. D. Stolarik, and J. P. Heppner, Electric fields in the vicinity of auroral forms from motions of barium vapor releases, J. Geophys. Res., 74, 3469-3487, 1969.

Williams, P. J. S., G. O. L. Jones, B. Jones, and H. Opgenoorth, High resolution measurements of magnetospheric electric fields, J. Atmos. Terr. Phys., 52, 439-448, 1990.

Yeoman, T. Y., I. K. Milling and D. Orr, Pi 2 pulsation polarization patterns on the U.K. Sub-Auroral Network (SAMNET), Planet. Space Sci., 38, 589, 1990.

A. D. Aylward, N. G. J. Gazey, and M. Lockwood, EISCAT Group, R25, Rutherford Appleton Laboratory, Chilton, Oxfordshire, OX11 0QX, England. (e-mail: alan@eiscat.ag.rl.ac.uk; nickgjg@eiscat.ag.rl.ac.uk; mike@eiscat.ag.rl.ac.uk.)

R. J. Bunting, Department of Physics, York University, York, YO1 5DD, England. (e-mail: robert@aurora.york.ac.uk)

S. Coles and P. N. Smith, Space Science Centre, Sussex University, Falmer, Brighton, BN1 9QH, England. (e-mail: tapt0@central.sussex.ac.uk; mpff9@central.sussex.ac.uk.)

M. Lester and T. K Yeoman, Department of Physics and Astronomy, Leicester University, Leicester, LE1 7RH, England.(e-mail:mle@ion.le.ac.uk; yxo@ion.le.ac.uk.)

H. Lühr, Institut für Geophysik und Meteorologie, Mendelssohnstraße, 38106 Brauschweig, Germany. (e-mail: luehr@geophys.nat.tu-bs.de)

(Received March 23, 1994; revised July 27, 1994; accepted August 29, 1994.) 